\title{
Globalization and the diffusion of ideas: why we should acknowledge the roots of mainstream ideas in global health
}

\author{
Emilie Robert $^{1{ }^{*}}$, Mohammad Hajizadeh ${ }^{2}$, Rowan El-Bialy ${ }^{3}$, Sayema Haque Bidisha $^{4}$
}

\begin{abstract}
Although globalization has created ample opportunities and spaces to share experiences and information, the diffusion of ideas, especially in global health, is primarily influenced by the unequal distribution of economic, political and scientific powers around the world. These ideas in global health are generally rooted in High-Income Countries (HICs), and then reach Low- and Middle-Income Countries (LMICs). We argue that acknowledging and addressing this invisible trend would contribute to a greater degree of open discussions in global health. This is expected to favor innovative, alternative, and culturally sound solutions for persistent health problems and reducing inequities.

Keywords: Globalization, Health Policy, Diffusion of Ideas, User Fees, International Classification of Diseases Copyright: ๑ 2014 by Kerman University of Medical Sciences

Citation: Robert E, Hajizadeh M, El-Bialy R, Bidisha SH. Globalization and the diffusion of ideas: why we should acknowledge the roots of mainstream ideas in global health. Int J Health Policy Manag 2014; 3: 7-9. doi: $10.15171 /$ ijhpm.2014.55
\end{abstract}

Article History:

Received: 2 April 2014 Accepted: 2 June 2014 ePublished: 3 June 2014

\author{
*Correspondence to: \\ Emilie Robert \\ Email: emilie.robert.3@umontreal.ca
}

$\mathrm{I}$ mproved transportation and communication facilities are among the many benefits of our globalized world. In the field of health, several international events, from UN Assemblies to scientific symposia, are organized each year gathering hundreds of people across the globe. For example, more than 1,800 participants from over 100 countries attended the second Global Symposium on Health Systems Research (1) organized in Beijing in November 2012. At the same time, the World Wide Web is becoming more and more accessible, facilitating the exchange of ideas through emails, discussion forums, and collaborative platforms. Open access scientific journals, as well as virtual communities of practice, which are networks of experts who interact on a regular basis to deepen their knowledge (2), are flourishing, both at national (e.g. Community of Practice in Ecosystem Approaches to Health in Canada) and international levels (e.g. Communities of Practice from Harmonization for Health in Africa). These initiatives have allowed the cross-fertilization and diffusion of ideas on different topics related to global health.

However, the other side of the coin is not that rosy. While globalization has increased opportunities and spaces to share and disseminate ideas, it has also allowed for various ideas emerging from High-Income Countries (HICs) to become mainstream or dominant in the global context. Ideas developed in HICs are often spread to Low- and MiddleIncome Countries (LMICs) whereas those developed in LMICs do not enjoy the same global influence, resulting in an unbalanced transfer of ideas. Such ideas emerging from HICs include economic thinking dominated by the neoliberal ideology (3), as well as approaches to health dominated by the biomedical model (4). At least two examples from the health sector readily illustrate this phenomenon: health system reforms, and the use of biomedical disease classifications.
These examples, discussed in detail below, demonstrate not only the unbalanced transfer of ideas on a global scale, but also the adverse health consequences that arise when ideas developed in HICs are implemented in LMICs with insufficient prior scrutiny or evaluation.

The first example deals with the issue of health user fees that became a major health financing mechanism in Africa and Asia over less than a decade. In line with the principles of the New Public Management, health user fees were strongly promoted by international organizations such as the World Bank, the World Health Organization (WHO) and UNICEF as a way to improve access to healthcare (5). According to them, under-funding of health systems in LMICs justified asking patients to contribute to care costs, while the worst-off would benefit from exemption. Transnational networks and elites, composed of academia and international experts from HICs, played a critical role in advocating health user fees (6). Their position in the global arena made them very influential among political decision-makers. So, despite insufficient evidence on the positive impact of this scheme on accessibility to healthcare, especially among vulnerable populations, user fees were widely implemented in LMICs. In practice, imposition of such fees has instead increased inequities in health financing and has created barriers to the access of healthcare (7). Many LMICs now eliminate health user fees in an attempt to reach the health Millennium Development Goals (8).

The second example deals with the international classification and diagnosis of diseases, particularly mental disorders. Most global mental health research relies on disease categories outlined in the International Classification of Disease (ICD) 10 and the American Psychiatric Association's Diagnostic and Statistical Manual (DSM-V). Many authors have argued that these categories of mental illness and their therapies 
are cultural products of a Western, biomedical conception of health and illness, and therefore their validity and effectiveness are not universal $(4,9,10)$. Regardless, mental illness categories in the ICD 10 and the DSM-V continue to guide non-governmental organizations' mental health interventions in LMICs, particularly during the aftermath of conflicts. In spite of the ineffectiveness of the diagnoses and treatments, the practice is still in place (11). Indeed, evidence demonstrates that imposing mental illness categories and therapies produced in HICs on LMICs, without considering their validity or effectiveness in each country's context, has the potential to disrupt healing systems already existing in those societies (12).

These examples demonstrate that global health ideas developed in HICs are often implemented in LMICs without being critically evaluated for effectiveness, cultural propriety, and possible unintended consequences. Transfer of ideas in global health is not a problem per se. However, ideas developed in HICs possess more global influence than do ideas developed in LMICs, which creates an unequal transfer. It should not come as a surprise that ideas flow more readily from HICs to LMICs than they do in the other direction. As a matter of fact, HICs concentrate the world's economic powers, as the acronym reveals. According to the World Bank's World Development Indicators, the GDP per capita (constant 2000 US dollars) for HICs and LMICs in 2012 were 30,756 and 2,383 US dollars, respectively (13). These resources account for the massive development assistance funding from HICs: considering bilateral donors only, it is estimated that they channeled 37\% of Development Assistance for Health (DAH) in 2013 (14). Moreover, HICs centralize the world's political powers. Indeed, governments from HICs occupy key positions in powerful international institutions, whose headquarters are located in HICs' economic and political capitals, such as the World Bank, the WHO or the World Trade Organization (WTO). These actors are thus at the forefront of international agenda setting and international policies formulation. HICs also concentrate the world's scientific powers. They house the most prestigious and world-renowned universities, think tanks and research institutes, attracting thousands of students and researchers from around the world. For example, 77\% of all foreign students were enrolled in universities in OECD countries in 2009 (15). Thanks to investments in Research and Development, researchers from HICs have the resources to conduct their research and publish their work, unlike their counterparts from LMICs. Although research capacity is growing in middle-income countries, it has not yet improved in low-income countries, as shown in the field of health policy and systems research (16).

Although we acknowledge that globalization has brought numerous opportunities for sharing ideas in health-related issues, we believe that ignoring-consciously or not-the global trend of uncritically diffusing ideas from HICs to LMICs might have serious consequences. That is why we must be aware of the existing imbalance and any reformist steps must acknowledge such imbalance, especially now that the post-2015 development agenda is being discussed. Researchers and practitioners in HICs should welcome, value, and more actively engage with researchers, practitioners, and intellectuals in LMICs. Meanwhile, collaboration at sub-regional and regional levels among LMICs should be improved. The role of emerging economies, such as Brazil, China, India, South Africa, in promoting these collaborations (17) is beneficial, as long as it does not aim to impose new standards but rather favor dialogue. We also strongly support debates of ideas and encourage critical minds through learning and capacity building. We believe that these actions will favor alternative and culturally sound solutions for persistent health problems and reducing inequities.

\section{Acknowledgements}

This perspective was written in the frame of a summer school organized by the Global Health Research Capacity Strengthening Program (http://www.pifrsm-ghrcaps.org) in 2013.

\section{Ethical issues}

Not applicable.

\section{Competing interests}

The authors declare that they have no competing interests.

\section{Authors' contributions}

ER wrote the first draft, excluding the section presenting the second example on the International classification of disease, which was written by REB and SHB. MH substantially improved the manuscript. All authors commented on the successive versions of the manuscript.

\section{Authors' affiliations}

1 University of Montreal Hospital Centre-Research Centre (CR-CHUM), University of Montréal, Montreal, Quebec, Canada. ${ }^{2}$ Institute for Health and Social Policy, McGill University, Montreal, Quebec, Canada. ${ }^{3}$ Division of Community Health and Humanities, Faculty of Medicine, Memorial University of Newfoundland, St. John's, Newfoundland and Labrador, Canada. ${ }^{4}$ Department of Economics, University of Dhaka, Dhaka, Bangladesh.

\section{References}

1. Second Global Symposium on Health Systems Research. Global Symposium on Health Systems Research (HSR). Beijing, People's Republic of China, 31 October - 3 November. 2012. Available from: http://www.healthsystemsresearch.org/hsr2012/

2. Wenger E, McDermott R, Snyder WM. A Guide to Managing Knowledge: Cultivating Communities of Practice. Boston: Harvard Business School Press; 2002.

3. Sen K, Koivusalo M. Health care reforms and developing countries-a critical overview. Int J Health Plann Manage 1998; 13: 199_ 215. doi: 10.1002/(sici)1099-1751(1998070)13:3\%3C199::aidhpm518\%3E3.3.co;2-t

4. Kleinman A. The Illness Narratives: Suffering, Healing and the Human Condition. New York, NY: Basic Books, Inc.; 1988.

5. De Ferranti D. Paying for health services in developing countries: a call for realism. World Health Forum 1985; 6: 99-105.

6. Lee K, Goodman H. Global policy networks: the propagation of health care financing reform since the 1980s. In: Lee K, K Buse, S Fustukian, editors. Health Policy in a Globalising World. Cambridge, MA: Cambridge University Press; 2002. p. 97-119.

7. Gilson L, Mclntyre D. Removing user fees for primary care in Africa: the need for careful action. BMJ 2005; 331: 762-5. doi: 10.1136/bmj.331.7519.762

8. Robert E, Samb OM. Pour une cartographie des soins de santé gratuits en Afrique de l'Ouest. Afr Contemp 2012; 3/2012: 100-1. doi: 10.3917/afco.243.0100

9. Summerfield D. Cross-cultural Perspectives on the Medicalization 
of Human Suffering. In: Rosen GM, editor. Posttraumatic Stress Disorder: Issues and Controversies. Chicester: John Wiley \& Sons Ltd; 2004. p. 233-45.

10. Summerfield $D$. How scientifically valid is the knowledge base of global mental health? BMJ 2008; 336: 992-4. doi: 10.1136/ bmj.39513.441030.ad

11. McKenzie K, Patel V, Araya R. Learning from low income countries: mental health. BMJ 2004; 329: 1138-40. doi: 10.1136/ bmj.329.7475.1138

12. Argenti-Pillen AM. The global flow of knowledge on war trauma: The role of the "Cinnamon Garden culture" in Sri Lanka. In: Pottier J, P Sillitoe, A Bicker, editors. Negotiating Local Knowledge: Identity, Power and Situated Practice in Development Intervention. London: Pluto Press; 2003. p. 189-214.

13. The World Bank. The World Bank DataBank [internet]. 2013. Available from: http://databank.worldbank.org/data/home.aspx
14. Dieleman JL, Graves CM, Templin T, Johnson E, Baral R, Leach-Kemon K, et al. Global Health Development Assistance Remained Steady In 2013 But Did Not Align With Recipients' Disease Burden. Health Aff (Millwood) 2014; 33: 878-86. doi: 10.1377/hlthaff. 2013.1432

15. OECD. Education at a Glance 2011: OECD Indicators [internet]. 2011. Available from: http://dx.doi.org/10.1787/eag-2011-en

16. Adam T, Ahmad S, Bigdeli M, Ghaffar A, Rottingen JA. Trends in health policy and systems research over the past decade: still too little capacity in low-income countries. PLoS One 2011; 6: e27263. doi: 10.1371/journal.pone.0027263

17. Bliss KE. Key Players in Global Health: How Brazil, Russia, India, China, and South Africa are influencing the game. A report of the CSIS Global Health Policy Center. Washington: Center for Strategic and International Studies; 2010. 